\title{
KETAHANAN LIMA JENIS KAYU TERHADAP TIGABELAS JAMUR PERUSAK KAYU
}

\author{
(The Resistance of Five Wood Species Against \\ Thirteen Wood Destroying Fungi)
}

\author{
Oleh/By : \\ Sihati Suprapti, Djarwanto \& Hudiansyah
}

\begin{abstract}
The resistance of five wood species originated from West Java against 13 wood destroying fungi were evaluated using modified-DIN 52176 standard. Wood samples were divided into two groups based on their radial surfaces, namely outer and inner parts of logs. Results showed that marasi ( Hymenaea courbaril L.), was moderately resistant against 13 fungal attacks (Class III). Meanwbile, asam jawa (Tamarindus indica L.), balobo (Diplodiscus sp. (?), kundang (Ficus variegata Bl.) and kendal (Ehretia accuminata R. Br.) were not durable (Class IV). Based on two groups of samples, weight loss percentage of the inner part, i.e. 10.4\%, was lower than that of the outer part of log, i.e. about $12.4 \%$. Both the inner and outer parts of logs had similar resistance, categorized as not durable (class IV). The highest weight loss percentage was encountered on the innerpart of kundang wood exposed to Pycnoporus sanguineus HHB324 culture (40.5\%), while the lowest was on the inner part of kendal wood exposed to Dacryopinax spathularia $(1.1 \%)$. Among the fungi species, the most severe attacks were encountered at Pycnoporus sanguineus HHB-324.
\end{abstract}

Keywords: Resistance, wood destroying fungi, weight loss

\begin{abstract}
ABSTRAK
Ketahanan lima jenis kayu yang berasal dari Jawa Barat diuji terhadap 13 jamur perusak menggunakan standar DIN 52176 yang telah dimodifikasi. Contoh uji kayu dibagi dalam dua kelompok secara radial, yaitu bagian tepi dan dalam dolok. Hasil penelitian menunjukkan bahwa kayu marasi (Hymenaea courbaril L.) termasuk kelompok kayu agak-tahan (kelas III), sedangkan kayu asam jawa (Tamarindus indica L.), balobo (Diplodiscus sp. (?), kundang (Ficus variegata Bl.) dan kendal (Ehretia accuminata R. Br.) termasuk kelompok kayu tidak-tahan (kelas IV). Berdasarkan dua kelompok contoh uji, kehilangan berat kayu bagian dalam sebesar 10,4\%, yang lebih rendah dibandingkan dengan kayu bagian tepi dolok sebesar 12,4\%. Kedua bagian dalam dan tepi dolok tersebut termasuk kelas ketahanan yang sama yaitu kelompok kayu tidak-tahan (kelas IV). Kehilangan berat tertinggi terjadi pada kayu kundang bagian dalam yang diletakkan pada biakan jamur Pycnoporus sanguineus HHB-324 (40,5\%). Sedangkan kehilangan berat terendah terjadi pada kayu kendal bagian dalam yang diletakkan pada biakan jamur Dacryopinax spathularia (1,1\%). Berdasarkan kemampuan melapukkan kayu, kemampuan tertinggi dijumpai pada Pycnoporus sanguineus HHB-324.
\end{abstract}

Kata kunci: Ketahanan kayu, jamur perusak, kehilangan berat 


\section{PENDAHULUAN}

Kayu kurang dikenal sudah mulai banyak dimanfaatkan untuk memasok industri perkayuan, namun dalam pemakaiannya umumnya belum dikelompokkan sesuai dengan sifat kayunya sehingga nilai tambahnya belum nyata. Kayu kurang dikenal umumnya dikelompokkan ke dalam jenis kayu rimba campuran, yang kualitasnya dianggap rendah, dengan tarif iuran hasil hutan (IHH) paling murah. Akibat kurang dikenalnya kayu, baik jenis maupun sifatnya, dalam pemakaian sering tercampur aduk antara kayu yang memiliki kualitas rendah dan tinggi untuk berbagai tujuan pemakaian, terutama untuk perumahan dan gedung. Semakin langka dan mahalnya kayu dari pohon tua atau kayu berdiameter besar sebagai akibat dari merosotnya produktivitas dan menyempitnya hutan alam serta meningkatnya kebutuhan kayu, maka peranan dan kontribusi kayu kurang dikenal tersebut akan semakin penting dalam mencukupi berbagai kebutuhan.

Informasi mengenai sifat dan kegunaan kayu masih sangat sedikit atau kurang memadai. Untuk melengkapi data tersebut maka penelitian sifat dasar dan kegunaan kayu andalan setempat yang kurang dikenal perlu dilakukan antara lain sifat ketahanan terhadap jamur perusak, dimana dapat mempengaruhi umur pakai kayu. Kayu yang memiliki kelas kuat tinggi tidak ada artinya apabila kelas awetnya rendah sebab umur pakainya akan pendek (rendah). Oleh karena itu, sifat ketahanan kayu terhadap jamur termasuk salah satu sifat yang penting pada kayu. Ketahanan kayu merupakan daya tahan suatu jenis kayu terhadap organisme perusak antara lain jamur pelapuk. Ketahanan kayu terhadap jamur merupakan salah satu parameter yang penting dalam pengolahan kayu. Posisi kayu di dalam dolok yaitu bagian dalam (dianggap sebagai teras) dan bagian tepi (dianggap sebagai gubal), diduga berbeda ketahanan terhadap jamur perusak. Penelitian ini dilakukan untuk mengetahui ketahanan kayu bagian dalam dan tepi dolok lima jenis kayu asal Jawa Barat terhadap serangan jamur perusak (pelapuk) secara laboratoris. Hasil penelitian ini diharapkan dapat digunakan untuk melengkapi bahan acuan dalam petunjuk pemanfaatan kayu yang tepat.

\section{BAHAN DAN METODE}

\section{A. Bahan}

Jamur. Jenis jamur penguji yaitu Chaetomum globossum FRI Japan-5-1, Coriolus versicolor FRI Japan-1030, Dacryopinax spathularia HHB-145, Lentinus lepideus Mad.-534, Phlebia brevispora Mad., Pycnoporus sanguineus HHB-324, Pycnoporus sanguineus HHB-8149, Polyporus sp. HHB-209, Postia placenta Mad.-696, Phanerochaete chrysosporium HHB-320, Schizophyllum commune HHB204, Trametes sp. HHB-332, dan Tyromycespalustris FRI Japan-507.

Media. Media untuk pertumbuhan jamur adalah MEA (malt-ekstrak-agar) dengan komposisi malt-ekstrak 3\% dan bacto-agar 2\% dalam air suling dan khusus untuk Chaetomium globosum menggunakan media PDA (Potato dextrose agar) 39 gram per liter air suling.

Kayu. Contoh uji berupa balok berukuran $5 \mathrm{~cm}$ x 2,5 $\mathrm{cm}$ x 1,5 cm, dengan $5 \mathrm{~cm}$ panjang kearah serat, yang dibuat dari bagian tepi $(1 \mathrm{~cm}$ dari luar) dan bagian dalam $(2 \mathrm{~cm}$ dari titik pusat diameter) dolok lima jenis kayu yang berasal dari Jawa Barat (Tabel 1). 
Tabel1. Jenis kayu yang diteliti ketahanannya terhadap jamur perusak Table 1. The wood species tested of their resistance against to wood destroying fungi

\begin{tabular}{|c|l|l|l|l|c|}
\hline No & \multicolumn{1}{|c|}{$\begin{array}{c}\text { Jenis kayu } \\
\text { (Wood species) }\end{array}$} & $\begin{array}{c}\text { Nama daerah } \\
\text { (Local name })\end{array}$ & $\begin{array}{c}\text { Suku } \\
\text { (Family) }\end{array}$ & $\begin{array}{c}\text { Asal } \\
\text { (Origin) }\end{array}$ & $\begin{array}{c}\text { Nomor register } \\
\text { (Registered } \\
\text { number })\end{array}$ \\
\hline 1 & Hymenaea courbaril L. & Marasi & Caesalpiniaceae & Cikampek & 34302 \\
\hline 2 & Tamarindus indica L. & Asam-jawa & Caesalpiniaceae & Karawang & 34303 \\
\hline 3 & Diplodiscus sp. (?) & Balobo & Euphorbiaceae & Sukabumi & 34304 \\
\hline 4 & Ficus variegata Bl. & Kundang & Moraceae & Sukabumi & 34305 \\
\hline 5 & Ebretia accuminata R. Br. & Kendal & Boraginaceae & Sukabumi & 34306 \\
\hline
\end{tabular}

\section{B. Metode}

Metode penelitian yang digunakan yaitu metode Kolle-flash, sesuai dengan pengujian pelapukan kayu terhadap jamur, menurut standar DIN-52176 yang dimodifikasi oleh Martawijaya (1975). Media yang telah dilarutkan secara homogen dimasukkan ke dalam piala Kolle sebanyak $80 \mathrm{ml}$ per-piala. Mulut piala disumbat dengan kapas steril, kemudian disterilkan menggunakan autoklaf pada suhu $121^{\circ} \mathrm{C}$, tekanan 1,5 atmosfer, selama 30 menit. Setelah dingin media diinokulasi dengan biakan murni jamur penguji, selanjutnya disimpan di ruang inkubasi sampai pertumbuhan miseliumnya merata dan menebal. Contoh uji yang telah diketahui berat kering mutlaknya dimasukkan ke dalam piala yang berisi biakan jamur tersebut. Setiap piala diisi dua buah contoh uji yang terdiri dari bagian tepi dan bagian dalam dolok, diletakkan sedemikian rupa sehingga tidak saling bersinggungan, dan diinkubasikan selama 12 minggu. Untuk setiap jenis kayu dan jenis jamur disediakan 5 buah piala. Pada akhir percobaan contoh uji dikeluarkan dari piala, dibersihkan dari miselium yang melekat secara hati-hati, dan ditimbang pada kondisi sebelum dan sesudah dikeringkan dengan oven, guna mengetahui persentase kehilangan beratnya.

Persentase kehilangan berat contoh uji akibat serangan masing-masing jenis jamur di analisa menggunakan rancangan percobaan acak lengkap berpola faktorial 5x2x13 (jenis kayu, bagian kayu dalam dolok dan jenis jamur), dengan lima kali ulangan. Rata-rata persentase kehilangan berat kayu dikelompokkan dengan menggunakan nilai atau skala kelas resistensi menurut Martawijaya (1975) sesuai Tabel 2.

\section{HASIL DAN PEMBAHASAN}

Adanya kerusakan atau pelapukan kayu ditandai antara lain terjadinya kehilangan berat contoh uji. Pada Tabel 3 dan 4 disajikan data rata-rata kehilangan berat contoh uji kayu bagian dalam dan tepi dolok. Kehilangan berat kayu bagian tepi dan dalam dolok yang disebabkan serangan jamur perusak (pelapuk), nampak bervariasi. Hasil analisis statistik menunjukkan bahwa jenis kayu, bagian kayu dalam dolok dan jenis jamur mempengaruhi kehilangan berat contoh uji $(\mathrm{P}<0.01)$. Ditunjukkan bahwa rata-rata kehilangan berat kayu oleh serangan tigabelas jamur perusak seperti tercantum pada Tabel 5. Hasil uji beda Tukey $(\mathrm{P}<0.05)$ memperlihatkan bahwa kehilangan berat terendah terjadi pada kayu marasi (Hymenaea courbaril 
Tabe1 2. Klasifikasi ketahanan kayu berdasarkan persentase kehilangan berat oleh serangan jamur

Table 2. Classification of wood resistance based on the weight loss due to fungi attack

\begin{tabular}{|c|l|l|}
\hline $\begin{array}{c}\text { Kelas } \\
(\text { Class })\end{array}$ & \multicolumn{1}{|c|}{ Resistensi (Resistance $)$} & \multicolumn{1}{|c|}{ Kehilangan berat (Weight loss), \% } \\
\hline I & Sangat tahan $($ Very resistant $)$ & Kecil atau tak berarti (None or negligible) \\
\hline II & Tahan (Resistant $)$ & Rata-rata $<5$ (Less than 5) \\
\hline III & Agak tahan $($ Moderately resistant) & Rata-rata $5-10$ (Less than 10) \\
\hline IV & Tidak tahan (Non-resistant) & Rata-rata $10-30(10$ to 30) \\
\hline V & Sangat tidak tahan (Perishable) & Rata-rata $>30$ (More than 30) \\
\hline
\end{tabular}

Sumber (Source): Martawijaya (1975).

L.). Sedangkan kehilangan berat tertinggi terjadi pada kayu kundang (Ficus variegata Bl.). Uji beda lanjut terhadap dua kelompok contoh uji berdasarkan Tukey $(\mathrm{P}<0.05)$ menunjukkan bahwa kehilangan berat pada kayu bagian dalam yaitu 10,4\% lebih rendah dibandingkan dengan kehilangan berat kayu bagian tepi yaitu 12,4\%, namun keduanya masih dikelompokkan ke dalam kelas ketahanan yang sama yaitu tidak-tahan (kelas IV). Dalam laporan sebelumnya dinyatakan bahwa kehilangan berat kayu bagian dalam lebih rendah dibandingkan dengan kehilangan berat kayu bagian tepi dolok (Djarwanto et al., 2001; Suprapti et al., 2004, dan Suprapti dan Krisdianto, 2006). Suprapti dan Djarwanto (2001a) menyatakan bahwa kayu yang berasal dari bagian tengah dolok umumnya lebih tahan terhadap serangan jamur perusak dibandingkan dengan kayu yang berasal dari bagian tepi dolok.

Ketahanan suatu jenis kayu dapat beragam tergantung pada bagian kayu dalam pohon dan jenis jamur yang menyerangnya. Berdasarkan klasifikasi ketahanan atau resistensi kayu terhadap jamur perusak di laboratorium maka kayu marasi termasuk kelompok kayu agaktahan (kelas III) dan kayu asam jawa, balobo, kundang dan kendal termasuk kelompok kayu tidak-tahan (kelas IV). Kelas ketahanan kayu marasi sama dengan kelas ketahanan yang dilaporkan Oey Djoen Seng (1990). Sedangkan kayu asam jawa dan kundang memiliki kelas ketahanan yang lebih tinggi atau lebih tahan terhadap serangan organisme perusak. Dan kelas ketahanan kayu kendal lebih rendah dibandingkan dengan laporan Oey Djoen Seng (1990), yang dinilai berdasarkan umur pakai kayu dengan tidak disebutkan organisme yang menyerang secara spesifik (Tabel 6). Menurut Oey Djoen Seng (1990) lima jenis kayu tersebut termasuk kelompok kayu sangat tahan sampai sangat tidak-tahan (kelas I-V). Kenaikan ketahanan karena proses pembentukan teras untuk beberapa jenis kayu dapat bervariasi. Tabel 5 menunjukkan bahwa ketahanan kayu marasi bagian tepi lebih rendah (kelas IV) dibandingkan dengan bagian dalam dolok (kelas II), yang dapat dikelompokkan ke dalam kriteria kenaikan ketahanan sedang. Hal yang sama juga ditemukan pada kayu kendal bagian tepi lebih rendah (kelas IV) dibandingkan dengan bagian dalam dolok (kelas III), yang dikelompokkan ke dalam kriteria kenaikan ketahanan sangat sedang. Hal ini mungkin 
Tabel3. Persentase kehilangan berat kayu bagian dalam dolok dan kelas resistensinya

Table 3. Percentage of weight loss and resistance class of inner part logs

\begin{tabular}{|l|c|c|c|c|c|}
\hline \multirow{2}{*}{ Jenis jamur (Fungi species) } & \multicolumn{5}{|c|}{$\begin{array}{l}\text { Persentase kehilangan berat dan kelas resistensi menurut } \\
\text { jenis kayu (Weight loss percentage and resistance class by wood } \\
\text { species) }\end{array}$} \\
\cline { 2 - 6 } & Marasi & Asam-jawa & Balobo & Kundang & Kendal \\
\hline Chaetomium globosum & $2,0 \mathrm{II}$ & $7,9 \mathrm{III}$ & $5,0 \mathrm{III}$ & $9,3 \mathrm{III}$ & $3,8 \mathrm{II}$ \\
\hline Coriolus versicolor & $8,3 \mathrm{III}$ & $20,4 \mathrm{IV}$ & $7,0 \mathrm{III}$ & $24,0 \mathrm{IV}$ & $17,8 \mathrm{IV}$ \\
\hline Dacryopinax spathularia & $1,9 \mathrm{II}$ & $5,8 \mathrm{III}$ & $4,6 \mathrm{II}$ & $10,2 \mathrm{IV}$ & $1,1 \mathrm{II}$ \\
\hline Lentinus lepideus & $3,0 \mathrm{II}$ & $2,7 \mathrm{II}$ & $5,9 \mathrm{III}$ & $3,1 \mathrm{II}$ & $1,2 \mathrm{II}$ \\
\hline Phanerochaete chrysosporium & $1,4 \mathrm{II}$ & $9,1 \mathrm{III}$ & $4,5 \mathrm{II}$ & $2,32 \mathrm{II}$ & $2,3 \mathrm{II}$ \\
\hline Phlebia brevispora & $6,3 \mathrm{III}$ & $8,2 \mathrm{III}$ & $11,2 \mathrm{IV}$ & $16,9 \mathrm{IV}$ & $7,6 \mathrm{III}$ \\
\hline Polyporus sp. & $3,8 \mathrm{II}$ & $20,1 \mathrm{IV}$ & $18,6 \mathrm{IV}$ & $11,5 \mathrm{IV}$ & $15,2 \mathrm{IV}$ \\
\hline Postia placenta & $1,7 \mathrm{II}$ & $4,9 \mathrm{II}$ & $5,5 \mathrm{III}$ & $10,6 \mathrm{IV}$ & $1,8 \mathrm{II}$ \\
\hline Pycnoporus sanguineus HHB-324 & $10,8 \mathrm{IV}$ & $16,9 \mathrm{IV}$ & $29,7 \mathrm{IV}$ & $40,5 \mathrm{~V}$ & $22,6 \mathrm{IV}$ \\
\hline P. sanguineus HHB-8149 & $2,9 \mathrm{II}$ & $7,4 \mathrm{III}$ & $7,0 \mathrm{III}$ & $34,8 \mathrm{IV}$ & $21,3 \mathrm{IV}$ \\
\hline Schizophyllum commune & $8,2 \mathrm{III}$ & $9,9 \mathrm{III}$ & $11,1 \mathrm{IV}$ & $12,8 \mathrm{IV}$ & $12,2 \mathrm{IV}$ \\
\hline Trametes sp. & $2,9 \mathrm{II}$ & $7,6 \mathrm{III}$ & $8,1 \mathrm{III}$ & $3,1 \mathrm{II}$ & $2,2 \mathrm{II}$ \\
\hline Tyromyces palustris & $2,2 \mathrm{II}$ & $27,3 \mathrm{IV}$ & $25,5 \mathrm{IV}$ & $26,5 \mathrm{IV}$ & $10,5 \mathrm{IV}$ \\
\hline
\end{tabular}

Keterangan (Remarks) : Angka romawi menunjukkan kelas resistensi kayu (Roman numbers show the resistance class of wood)

disebabkan oleh adanya zat ekstraktif (pengawet) yang terbentuk pada waktu terjadinya kayu teras (pada kayu bagian dalam). Selain itu kayu marasi berasal dari dolok diameter besar (69 $\mathrm{cm}$ ) sehingga kemungkinan zat ekstraktif kayu pada bagian dalam yang terbentuk lebih besar. Sedangkan ketiga jenis kayu yaitu asam jawa, balobo dan kundang baik bagian tepi maupun dalam dolok memiliki kelas ketahanan yang sama (kelas IV), sehingga kenaikan ketahanannya kurang nyata. Hal ini mungkin karena kayu dari dolok diameter kecil (sekitar $30 \mathrm{~cm}$ ) masih termasuk kayu muda yang masih dalam pertumbuhan dan pembentukan teras. Berdasarkan hasil penelitian kayu kelas III-IV jika hendak dipakai sebagai bahan bangunan sebaiknya diawetkan terlebih dahulu guna mencegah serangan jamur perusak. Djarwanto dan Abdurrohim (2000) menyatakan bahwa kayu kelas III-IV jika hendak dipakai sebagai bahan bangunan sebaiknya diawetkan dengan mengunakan bahan kimia (pestisida) terlebih dahulu guna mencegah serangan jamur perusak sehingga usia pakainya dapat lebih panjang. 
Tabel 4. Persentase kehilangan berat kayu bagian tepi dolok dan kelas resistensinya Table 4. Percentage of weight loss and resistance class of outer part logs

\begin{tabular}{|l|r|r|r|r|r|}
\hline \multirow{2}{*}{ Jenis jamur (Fungi species) } & \multicolumn{5}{|c|}{$\begin{array}{r}\text { Persentase kehilangan berat dan kelas resistensi } \\
\text { menurut jenis kayu (Weight loss percentage and resistance } \\
\text { class by wood species) }\end{array}$} \\
\cline { 2 - 6 } & Marasi & Asam- jawa & Balobo & Kundang & Kendal \\
\hline Chaetomium globosum & $3,2 \mathrm{II}$ & $6,7 \mathrm{III}$ & $17,0 \mathrm{IV}$ & $7,1 \mathrm{III}$ & $4,8 \mathrm{II}$ \\
\hline Coriolus versicolor & $20,4 \mathrm{IV}$ & $22,3 \mathrm{IV}$ & $5,2 \mathrm{III}$ & $18,5 \mathrm{IV}$ & $16,4 \mathrm{IV}$ \\
\hline Dacryopinax spathularia & $4,7 \mathrm{II}$ & $6,1 \mathrm{III}$ & $4,8 \mathrm{II}$ & $8,0 \mathrm{III}$ & $3,6 \mathrm{II}$ \\
\hline Lentinus lepideus & $17,9 \mathrm{IV}$ & $3,7 \mathrm{II}$ & $6,3 \mathrm{III}$ & $3,4 \mathrm{II}$ & $5,5 \mathrm{III}$ \\
\hline Phanerochaete chrysosporium & $2,7 \mathrm{II}$ & $11,3 \mathrm{IV}$ & $3,9 \mathrm{II}$ & $11,8 \mathrm{IV}$ & $4,8 \mathrm{II}$ \\
\hline Phlebia brevispora & $9,2 \mathrm{III}$ & $9,9 \mathrm{III}$ & $7,5 \mathrm{III}$ & $13,4 \mathrm{IV}$ & $8,3 \mathrm{III}$ \\
\hline Polyporus sp. & $20,4 \mathrm{IV}$ & $18,3 \mathrm{IV}$ & $17,2 \mathrm{IV}$ & $5,4 \mathrm{III}$ & $12,9 \mathrm{IV}$ \\
\hline Postia placenta & $3,6 \mathrm{II}$ & $5,2 \mathrm{III}$ & $5,3 \mathrm{III}$ & $6,0 \mathrm{III}$ & $6,3 \mathrm{III}$ \\
\hline Pycnoporus sanguineus HHB-324 & $23,6 \mathrm{IV}$ & $25,2 \mathrm{IV}$ & $26,7 \mathrm{IV}$ & $39,7 \mathrm{~V}$ & $25,2 \mathrm{IV}$ \\
\hline P. sanguineus HHB-8149 & $9,5 \mathrm{III}$ & $9,2 \mathrm{III}$ & $7,3 \mathrm{III}$ & $26,5 \mathrm{IV}$ & $19,4 \mathrm{IV}$ \\
\hline Schizophyllum commune & $18,8 \mathrm{IV}$ & $14,3 \mathrm{IV}$ & $8,8 \mathrm{III}$ & $12,4 \mathrm{IV}$ & $11,2 \mathrm{IV}$ \\
\hline Trametes sp. & $13,0 \mathrm{IV}$ & $6,6 \mathrm{III}$ & $7,6 \mathrm{III}$ & $2,7 \mathrm{II}$ & $3,6 \mathrm{II}$ \\
\hline Tyromyces palustris & $29,1 \mathrm{IV}$ & $27,8 \mathrm{IV}$ & $18,1 \mathrm{IV}$ & $23,9 \mathrm{IV}$ & $26,3 \mathrm{IV}$ \\
\hline
\end{tabular}

Keterangan (Remarks) : Angka romawi menunjukkan kelas resistensi kayu (Roman numbers show the resistance class of wood)

Tabel 5. Rata-rata kehilangan berat dan kelas resistensi lima jenis kayu

Table 5. The average of weight loss and resistance class of five wood species

\begin{tabular}{|c|c|c|c|c|c|c|}
\hline \multirow[b]{2}{*}{$\begin{array}{l}\text { Nama } \\
\text { daeah } \\
\text { (Local } \\
\text { name) }\end{array}$} & \multirow[b]{2}{*}{$\begin{array}{l}\text { Jenis kayu } \\
\text { (Wood species) }\end{array}$} & \multirow{2}{*}{$\begin{array}{c}\text { Diameter } \\
\text { dolok } \\
\text { (Log } \\
\text { diameter), } \\
\mathrm{cm}\end{array}$} & \multicolumn{3}{|c|}{ Kehilangan berat (Weight loss), $\%$} & \multirow[b]{2}{*}{$\begin{array}{l}\text { Kelas } \\
\text { (Class) }\end{array}$} \\
\hline & & & $\begin{array}{c}\text { Bagian } \\
\text { dalam } \\
\text { (Inner part) }\end{array}$ & $\begin{array}{l}\text { Bagian tepi } \\
\text { (Outer part) }\end{array}$ & $\begin{array}{l}\text { Rata-rata } \\
\text { (Average) }\end{array}$ & \\
\hline Marasi & Hymenaea courbaril & 69,0 & 4,2 & 13,5 & $8,9 \mathrm{~d}$ & III (II-IV) \\
\hline Asam-jawa & Tamarindus indica & 36,5 & 11,4 & 12,8 & $12,1 \mathrm{~b}$ & IV (II-IV) \\
\hline Balobo & Diplodiscus sp. & 25,5 & 11,0 & 10,4 & $10,7 \mathrm{bc}$ & IV (II-IV) \\
\hline Kundang & Ficus variegata & 30,5 & 15,9 & 13,8 & $14,8 \mathrm{a}$ & IV (II-V) \\
\hline Kendal & Ehretia accuminata & 37,0 & 9,2 & 11,4 & $10,3 \mathrm{~cd}$ & IV (II-IV) \\
\hline
\end{tabular}

Keterangan (Remarks) : Angka-angka dalam kolom yang diikuti oleh huruf sama tidak berbeda nyata pada uji Tukey $\mathrm{P}<0.05$ (The numbers within the column followed by the same letter, are not significantly different, Tukey test $P<0.05$ ) 
Tabel 6. Kelas ketahanan dan kelas kuat lima jenis kayu Table 6. Resistance and strength classes of five wood species

\begin{tabular}{|c|c|c|c|c|c|}
\hline $\begin{array}{c}\text { Nama daerah } \\
\text { (Local name) }\end{array}$ & $\begin{array}{l}\text { Jenis kayu } \\
\text { (Wood species) }\end{array}$ & $\begin{array}{l}\text { Famili } \\
\text { (Family) }\end{array}$ & $\begin{array}{c}\text { Berat jenis } \\
\text { (Specific } \\
\text { gravity) }\end{array}$ & $\begin{array}{c}\text { Kelas awet } \\
\text { (Resistance } \\
\text { class) }\end{array}$ & $\begin{array}{c}\text { Kelas kuat } \\
\text { (Strength } \\
\text { class) }\end{array}$ \\
\hline Marasi & Hymenaea courbaril & Caesalpiniaceae & 0,73 & III & II \\
\hline \multirow[t]{2}{*}{ Asam-jawa } & \multirow[t]{2}{*}{ Tamarindus indica } & \multirow[t]{2}{*}{ Caesalpiniaceae } & 1,30 & I & I \\
\hline & & & 0,87 & $\mathrm{~V}$ & II \\
\hline Balobo & Diplodiscus sp.(?) & Euphorbiaceae & - & - & - \\
\hline Kundang & Ficus variegata & Moraceae & 0,29 & $\mathrm{~V}$ & V-(III) \\
\hline Kendal & Ehretia accuminata & Boraginaceae & 0,61 & III & II \\
\hline
\end{tabular}

Sumber (Source): Oey Djoen Seng (1990); - = tidak ada data (no data available)

Setiap jenis jamur memiliki kemampuan melapukkan atau merusak setiap jenis kayu yang dapat dipengaruhi oleh jenis kayunya dan jenis organismenya. Kemampuan jamur untuk melapukkan kayu beragam menurut jenis kayu yang digunakan dan jenis jamur yang menyerangnya, yang ditunjukkan dengan variasi besarnya kehilangan berat, sebagaimana ditelaah dengan uji beda Tukey pada P < 0.05 (Tabel 7). Kemampuan P. sanguineus HHB-324 dalam melapukkan kayu (26,1\%) lebih tinggi dibandingkan dengan kemampuan P. sanguineus HHB-8149 (14,5\%). Namun ketahanan kayunya masih termasuk kelas yang sama. Hal ini mungkin disebabkan karena strain jamur tersebut berlainan, yang ditunjukkan dengan penampakan warna miselium berbeda secara konsisten setelah terjadi penebalan. Dalam laporan sebelumnya (Suprapti dan Djarwanto, 2001b) dinyatakan bahwa pertumbuhan miselium P. sanguineus HHB-8149 pada permukaan media-agar dan balok kayu lebih lambat dibandingkan dengan pertumbuhan $P$. sanguineus HHB-324 (isolat asal Kalimantan Timur). Kemampuan jamur dalam melapukkan kayu tertinggi didapatkan pada Pycnoporus sanguineus HHB-324, kemudian T. palustris, dan Coriolus versicolor yang diikuti oleh Pycnoporus sanguineus HHB-8149 dan Polyporus sp., sedangkan kemampuan melapukkan yang rendah terjadi pada Postia placenta, Dacryopinax spathularia, Lentinus lepideus, Trametes sp., Phanerochaete chrysosporium dan Chaetomium globosum. Pada laporan sebelumnya disebutkan bahwa kemampuan yang tertinggi dalam melapukkan lima jenis kayu asal Jawa Barat, dijumpai pada C. versicolor, kemudian diikuti Pycnoporus sanguineus HHB-324, T. palustris, dan Polyporus sp., dan yang rendah pada Chaetomium globosum, D. spathularia, Phlebia brevispora, Pycnoporus sanguineus HHB-8149, dan Postia placenta (Suprapti et al., 2004), serta pada D. spathularia (terhadap kayu bagian dalam/teras) dan C. globosum terhadap kayu bagian tepi/gubal (Djarwanto et al., 2001). Menurut Suprapti et al. (2003), kemampuan melapukkan kayu tertinggi terjadi pada Polyporus sp., T. palustris, P. Sanguineus, HHB-324, dan L. lepideus, sedangkan kemampuan terendah terjadi pada P. chrysosporium, D. spathularia dan C. globosum.

Berdasarkan analisis statistik didapatkan interaksi yang nyata antara jenis kayu, bagian atau posisi kayu dalam dolok dan jenis jamur perusak $(\mathrm{P}<0.05)$. Interaksi yang kuat ditunjukkan dengan kehilangan berat tertinggi didapatkan pada bagian dalam kayu kundang yang diletakkan pada biakan Pycnoporus sanguineus HHB-324 yaitu 40,5\%. Sedangkan interaksi 
yang lemah yang ditunjukkan dengan kehilangan berat terendah terjadi pada bagian dalam kayu kendal yang diletakkan pada biakan Dacryopinax spathularia yaitu 1,1\%.

Tabel 7. Rata-rata kehilangan berat kayu oleh jamur perusak

Table 7. The average weight loss of wood due to destroying fungi

\begin{tabular}{|l|l|c|}
\hline \multicolumn{1}{|c|}{ Jenis jamur (Fungi species) } & \multicolumn{1}{|c|}{$\begin{array}{c}\text { Kelompok jamur } \\
\text { (Group of fung) }\end{array}$} & $\begin{array}{c}\text { Kehilangan berat } \\
\text { (Weight loss), \% }\end{array}$ \\
\hline Chaetomium globosum FRI Japan 5-1 & Pelunak (Soft rot fungi) & $6,7 \mathrm{f}$ \\
\hline Coriolus versicolor FRI Japan-1030 & Pelapuk putih (White rot fungi) & $16,0 \mathrm{c}$ \\
\hline Dacryopinax spathularia HHB-145 & Pelapuk coklat (Brown rot fungi) & $5,1 \mathrm{f}$ \\
\hline Lentinus lepideus Mad-534 & Pelapuk coklat (Brown rot fungi) & $5,3 \mathrm{f}$ \\
\hline Phanerochaete chrysosporium HHB-238 & Pelapuk putih (White rot fungi) & $6,2 \mathrm{f}$ \\
\hline Phlebia brevispora Mad. & Pelapuk putih (White rot fungi) & $9,9 \mathrm{e}$ \\
\hline Polyporus sp. HHB-209 & Pelapuk coklat (Brown rot fungi) & $14,4 \mathrm{~cd}$ \\
\hline Pycnoporus sanguineus HHB-324 & Pelapuk putih (White rot fungi) & $26,1 \mathrm{a}$ \\
\hline Pycnoporus sanguineus HHB-8149 & Pelapuk putih (White rot fungi) & $14,5 \mathrm{~cd}$ \\
\hline Postia placenta Mad-696 & Pelapuk putih (White rot fungi) & $4,3 \mathrm{f}$ \\
\hline Schizophyllum commune HHB-204 & Pelapuk putih (White rot fungi) & $12,0 \mathrm{de}$ \\
\hline Trametes sp. HHB-332 & Pelapuk (Wood rotting fung ) & $5,7 \mathrm{f}$ \\
\hline Tyromyces palustris FRI Japan-507 & Pelapuk coklat (Brown rot fungi) & $21,7 \mathrm{~b}$ \\
\hline
\end{tabular}

Keterangan (Remarks) : Angka-angka dalam kolom yang diikuti oleh huruf sama tidak berbeda nyata pada uji Tukey $\mathrm{P}<0.05$ (The numbers within the column followed by the same letter, are not significantly different, Tukey test $P<0.05$ )

\section{KESIMPULAN}

Dari lima jenis kayu yang diteliti didapatkan bahwa kayu marasi termasuk kelompok kayu agak-tahan (kelas III), sedangkan kayu asam jawa, balobo, kundang dan kendal termasuk kelompok kayu tidak-tahan (kelas IV). Berdasarkan dua kelompok contoh uji, kehilangan berat kayu bagian dalam sebesar 10,4\%, yang lebih rendah dibandingkan dengan kayu bagian tepi dolok sebesar 12,4\%. Kedua bagian dalam dan tepi dolok termasuk kelas ketahanan yang sama yaitu kelompok kayu tidak-tahan (kelas IV). Kehilangan berat tertinggi terjadi pada kayu kundang bagian dalam yang diletakkan pada biakan jamur Pycnoporus sanguineus HHB-324 (40,5\%). Sedangkan kehilangan berat terendah terjadi pada kayu kendal bagian dalam yang diletakkan pada biakan Dacryopinax spathularia (1,1\%). Berdasarkan kemampuan melapukkan kayu, kemampuan tertinggi dijumpai pada Pycnoporus sanguineus HHB-324. Sedangkan kemampuan melapukkan yang rendah terjadi pada Postia placenta, Dacryopinax spathularia, Lentinus lepideus, Trametes sp., Phanerochaete chrysosporium dan Chaetomium globosum. 


\section{DAFTAR PUSTAKA}

Djarwanto dan S. Abdurrohim. 2000. Teknologi pengawetan kayu untuk memperpanjang usia pakai. Buletin Kehutanan dan Perkebunan 1(2): 159-172. Badan Penelitian dan Pengembangan Kehutanan dan Perkebunan. Jakarta.

S. Suprapti dan Hudiansyah. 2001. Ketahanan lima jenis kayu dolok diameter kecil terhadap enam jenis jamur pelapuk. Prosiding Seminar Nasional III Masyarakat Peneliti Kayu Indonesia (MAPEKI) tanggal 22-23 Agustus 2000 di Bandung. Hlm.: 453-460. Fakultas Kehutanan Universitas Winayamukti. Bandung.

Martawijaya, A. 1975. Pengujian laboratoris mengenai keawetan kayu Indonesia terhadap jamur. Kehutanan Indonesia. Hlm.: 775-777. Direktorat Jenderal Kehutanan, Jakarta.

Oey Djoen Seng. 1990. Berat jenis dari jenis-jenis kayu Indonesia dan pengertian beratnya kayu untuk keperluan praktek. Pengumuman Nr. 13. Pusat Penelitian dan Pengembangan Hasil Hutan. Bogor.

Suprapti, S. and Djarwanto. 2001a. Decay resistance of some wood of small log diameter to the attack of white rot and brown rot fungi. Utilization of Small Diameter Logs. Report on the Collaboration Research Project of Indonesia-Republic of Korea. pp: 80-87. Pusat Penelitian dan Pengembangan Teknologi Hasil Hutan. Bogor.

- 2001b. Kemampuan sepuluh isolat jamur dalam melapukkan kayu. Prosiding Seminar Nasional III Masyarakat Peneliti Kayu Indonesia (MAPEKI) tanggal 22-23 Agustus 2000 di Bandung. Hlm.: 190-197. Fakultas Kehutanan Universitas Winayamukti. Bandung.

dan Hudiansyah. 2003. Ketahanan delapan jenis kayu terhadap duabelas jamur pelapuk. Prosiding Seminar Nasional V Masyarakat Peneliti Kayu Indonesia (MAPEKI) tanggal 30 Agustus 1 September 2002 di Bogor. Hlm.: 179184. Pusat Penelitian dan Pengembangan Teknologi Hasil Hutan. Bogor.

2004. Ketahanan lima jenis kayu terhadap beberapa jamur perusak kayu. Jurnal Penelitian Hasil Hutan 22 (4): 239-246. Pusat Penelitian dan Pengembangan Hasil Hutan. Bogor.

Suprapti, S. dan Krisdianto. 2006. Ketahanan empat jenis kayu hutan tanaman terhadap beberapa jamur perusak kayu. Jurnal Penelitian Hasil Hutan 24 (4): 267-274. Pusat Penelitian dan Pengembangan Hasil Hutan. Bogor. 